\title{
ELS CASTELLVELL DURANT EL SEGLE X, ARTÍFEXS I VEGUERS DE LA MARCA DE BARCELONA*
}

\author{
THE CASTELLVELL FAMILY IN THE TENTH CENTURY, \\ THE MAKERS AND VICARS OF THE MARCH OF BARCELONA
}

\author{
RAMON MARTÍ \\ Universitat Autònoma de Barcelona \\ http://orcid.org/0000-0003-3887-2165
}

\begin{abstract}
Resum: Aquest treball reprèn l'estudi sobre els orígens del llinatge baronial dels Castellvell, una família aristocràtica de Barcelona que remuntem fins la fi del segle IX. Propietaris de terres arreu d'aquest comtat, la vella fortificació de Castellvell de Rosanes constitueix el seu bastió principal i els procurà una notòria participació al procés expansiu que es verifica durant el segle X, quan es constitueix la Marca de Barcelona i es multipliquen les fortificacions. Aleshores els Castellvell destaquen entre altres veguers, tant per les seves funcions extraordinàries de representació comtal com per l'amplitud dels enllaços que practiquen amb les famílies vescomtals del seu entorn. Són qualitats que distingeixen un llinatge que és paradigmàtic durant aquests temps de profundes transformacions.
\end{abstract}

Mots clau: veguer; vescomte; llinatge; torre de guaita; castell; Barcelona.

\begin{abstract}
This paperresumes the study of the origins of the Castellvell baronial lineage. The Castellvells were an aristocratic family from manageBarcelona dating back to the late ninth century. They owned land all over the county. Their main stronghold was the old fortress of Castellvell de Rosanes from which they contributed significantly to the process of expansion that took place during the tenth century. ThereThis was the time when the March of Barcelona was established and many castles were built in all parts. The Castellvells stood out among the other leading families because of their extraordinary role as the Count's representatives and for the breadth of their relationships with the neighbouring families of viscounts. It is these attributes that distinguish a family that was paradigmatic in those years of profound transformations.
\end{abstract}

Keywords: vicar; viscount; lineage; watchtower; castle; Barcelona.

\section{SUMARI}

1. Les fortificacions situades a ponent del Llobregat i els seus artífexs.- 2 El veguer Sendred, membre d'un llinatge aristocràtic barceloní.- 3. L'hereu Onofre Amat, el veguer Ènnec Bonfilll i l'altre germà, Sendred Màger.- 4. Conclusions.- 5. Bibliografia citada.

\footnotetext{
* Recerca realitzada en el marc del projecte: Génesis de la nobleza medieval: fortificaciones y poderes territoriales en el nordeste peninsular durante los siglos VIII-XI (HAR201563661-P; MINECO - FEDER).
} 
Els Castellvell figuren entre els llinatges baronials més coneguts del comtat de Barcelona i això gràcies a una documentació generosa que ha atret l'interès dels analistes de temps enrere. Així, ben aviat els genealogistes van poder destriar un arbre familiar força sòlid, que es remuntava al segle $\mathrm{X}$ i que hom podia seguir detalladament fins la seva fusió amb la família dels Montcada al segle XIII. Són prova d'això les monografies de Fèlix Duran i, principalment, de Bonaventura Pedemonte, qui franqueja definitivament la barrera de l'any mil i se centra al nucli patrimonial del llinatge, construït principalment sobre el domini del Castellvell de Rosanes. Trenta anys enrere, Albert Benet va ser el primer en reconèixer el veguer Sendred com l'ancestre comú de les famílies nobiliàries de Cervelló, Castellvell i Castellet, quan identificava correctament els seus tres fills. Tot desenvolupant les perspectives d'anàlisi antropològica dels grups feudals plantejada per José Enrique Ruiz-Domènec, Blanca Garí aleshores també publicava el seu estudi particular sobre el llinatge dels Castellvell durant els segles XI-XII i, poc després, ratificava les propostes de Benet ${ }^{1}$.

D'aleshores ençà poques novetats cal observar en l'estudi de la fase inicial d'aquest llinatge, tot i que ha progressat molt l'edició sistemàtica de documents o que alguna precisió ha estat observada. Gràcies a això, avui podem conèixer molt millor la composició, el comportament i la política d'aliances que segueix aquest grup aristocràtic de bon començament. Així mateix, els progressos de l'arqueologia ara també ens ofereixen noves perspectives a tenir en compte en l'estudi de les fortificacions, atesa la implicació preferent d'aquesta família en el govern de la frontera del comtat de Barcelona. És amb noves eines que avui reprenem l'estudi dels orígens d'un llinatge que derivaria de l'aristocràcia carolíngia i que establiria relacions preferents amb certes famílies vescomtals, tot i que perseguim objectius més amplis que els d'un exercici de verificació genealògica. Assumida la seva importància, no dubtem que calia revisar i completar l'estudi de la fase inicial d'aquest llinatge, quan els Castellvell, entre d'altres, posseïren el càrrec de veguer comtal (vicarius).

${ }^{1}$ Duran 1927; Pedemonte 1929; Benet 1983; Ruiz-Domènec 1982; Garí 19851990. 


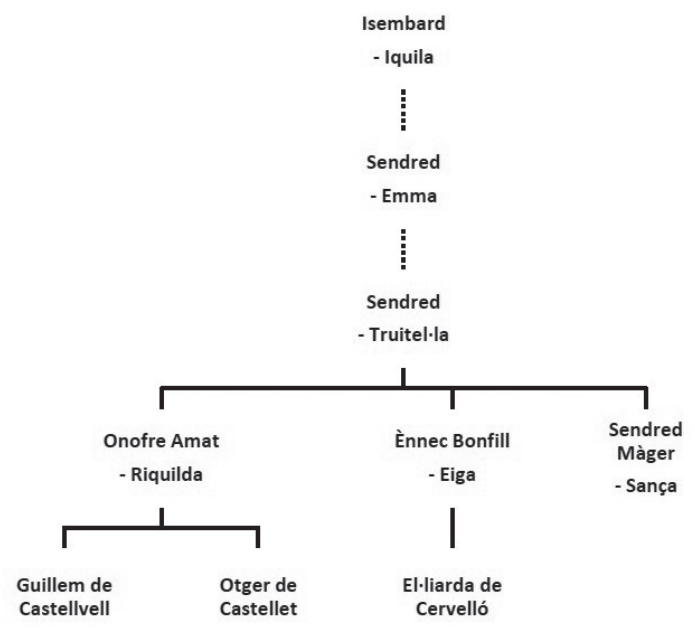

Fig. 1. Arbre genealògic dels Castellvell durant els segles IX-X.

\section{LES FORTIFICACIONS SITUADES A PONENT DEL LLOBREGAT I ELS SEUS ARTÍFEXS}

És ben conegut que durant el darrer quart del segle IX s'inicia una llarga fase d'enfrontaments bèl-lics que reporten notables avenços territorials als districtes comtals de Catalunya Vella. El procés s'enceta quan el comte Guifré el Pilós portà de nou la frontera al bell mig de Catalunya, fins l'eix dels rius Llobregat i Cardener, tot integrant diversos districtes al domini hereditari del llinatge comtal de Cerdanya. Bàsicament, és a partir d'ara quan comencen las sèries documentals als arxius, en sincronia amb la implantació del seu domini en cada zona, mentre es fixen els límits definitius dels diferents comtats. De fet, Abadal proposà que el govern del comtat de Barcelona seria concedit al comte Guifré mitjançant les disposicions secretes de l'assemblea de Troyes l'any 878, on es liquidaren els drets del marquès Bernat de Gòtia. També podria ser, però, que l'adquisició definitiva d'aquest comtat es produís mitjançant un pacte entre comtes i aclamació local que precedís de poc la mort de Guifré en combat l'any 897, potser a l'entorn del castell de Terrassa. En qualsevol cas, fins aleshores Sunyer d'Empúries hauria exercit una certa tutela del comtat, si més no d'ençà l'any 862, quan el rei Carles li concedí l'extens domini de Palautordera i del Montseny que havia estat del marquès Humfrid ${ }^{2}$.

\footnotetext{
${ }^{2}$ Abadal 1958; Martí 1997, pp. 50-62; Abadal 1926-1950,pp. 355-358.
} 
D'acord amb la documentació conservada, al comtat de Barcelona és a inicis del segle $\mathrm{X}$ quan s'observen els primers avenços territorials que superen el riu Llobregat, accions inicials que capitalitzen els vescomtes i el monestir de Sant Cugat del Vallès. Aquí el domini comtal es bastí de forma sistemàtica mitjançant l'establiment de castells termenats i també amb l'absorció d'anteriors cel-les o monestirs per part de Sant Cugat, accions que inicialment es limiten al Baix Llobregat i al sector oriental del massís del Garraf. Aquest és el cas del castell de Cervelló, amb una primera noticia autèntica de l'any 912 i on Sant Cugat manipulà documents que argumenten la concessió comtal del monestir o cel·la de Santa Creu. En 917 és el torn del castell de Subirats, prope territorio Penete$s e$, on el "marquès" Ermenard i son germà Udalard promovien la cristianització de la zona mitjançant la intervenció del monestir vallesà, al qual concedien les esglésies de Monistrol d'Anoia ${ }^{3}$. Correspon a l'any 928 la lectura equívoca d'un castell Ravinas que radica in latere monte de Begas i que el vescomte Lleopard venia a son fill Otger per mil sous, juntament amb la villla Campins del Montseny, una fortificació que cal identificar sense cap mena de dubte amb el castell d'Eramprunyà, també anomenat Rosanas inicialment ${ }^{4}$.

En qualsevol cas, la conquesta definitiva del sector ponentí del comtat de Barcelona no sembla que s'assoleixi fins la dècada dels anys vint del segle X. Seria aleshores quan les forces comtals ocuparien la totalitat de les comarques del Baix Llobregat, del Garraf i del Penedès, mentre el comtat de Manresa progressava fins els confins de la Conca de Barberà. De forma força imprecisa, les fonts locals permeten situar aquesta àmplia conquesta entre els anys 911-932, com s'infereix de la dotalia de l'església de Sant Miquel d'Olèrdola, on s'argumenta que fou en temps del comte Sunyer i del bisbe Teodoric (904-932) quan s'establí la jurisdicció d'aquest castell sobre un ampli terme. En això s'hi afegeix la signatura autògrafa de l'abat Déudonat de Sant Cugat (914-917) sobre l'ara d'altar de la cella de Sant Esteve de Castellet. Fins i tot els comtes empordanesos poden haver participat en la conquesta del Penedès, on sembla intervenir el comte Gausbert, un heroi triomfant segons la làpida commemorativa de restauració de Sant Martí d’Empúries en 926. A les fonts àrabs també trobem resposta, com és la rèplica de l'esquadra califal durant l'estiu de l'any 935 que devastà tota la costa, del comtat d'Empúries fins el Llobregat ${ }^{5}$. De fet, a partir d'aquí els autors àrabs consideren reiteradament que els dominis del comte de Barcelona s'estenen fins la ciutat de Tarragona, tot i que les forces comtals no aconseguiren ocupar-la.

\footnotetext{
${ }^{3}$ Rius 1945-1947, docs. 2, 4-5 i 9.

${ }^{4}$ Udina 1951, doc. 91; Rius 1945-1947, docs. 92, 115-116, 121, 129, 177 i 187, per exemple.

5 Martí 1992; Ordeig 1993-2001, doc. 108; Pladevall 1992, 1990; Bramon 2000, pp. 278-282.
} 
D'acord amb una copiosa i ben arrelada tradició historiogràfica, pot haver qui discuteixi si aquesta expansió comtal és fruit d'una conquesta militar o si, amb ella, culmina un procés repoblador de terres ermes i desertes, una hipòtesi que presenta seriosos inconvenients en cronologies tan reculades. Aquí la persistència de població autòctona i del cristianisme és ben testimoniada per diversos monestirs preexistents (monasteriola), que són nombrosos a les zones de fricció dels dominis islàmics amb els districtes comtals ${ }^{6}$. En són exemples els casos de Santa Creu de Cervelló, Monistrol d'Anoia o Sant Esteve de Castellet, entre d'altres, d'un extrem a l'altre d'aquestes comarques. També l'arqueologia comença a proporcionar dades significatives com succeeix a la ciutadella d'Olèrdola, on les datacions obtingudes a la necròpoli intramurs de Sant Miquel permeten remuntar-se a ple segle IX, si més no, tot $\mathrm{i}$ que no hi hagi inhumacions de ritus islàmic en aquest sector ${ }^{7}$. És fora de dubte, però, que aleshores aquests territoris depenien d'al-Andalus.

Ho confirma més tard el geògraf al-Idrīsī, quan relaciona diversos districtes $\left(a^{\prime} m \bar{a} l\right)$ de Barcelona situats de la banda d'al-Andalus i cita el pla del Penedès $(f a h s$ ), amb un castell homònim que tant podria al·ludir a Olèrdola com al Castellvell de la Marca. Major dificultat presenta la correlació certa d'altres tres territoris que indica i que corresponen al conjunt del Camp de Tarragona o les seves immediacions ${ }^{8}$. Són districtes que en ple segle IX graviten sota l'òrbita de la ciutat de Tortosa, com es desprèn de la carta que el governador 'Ubayd Al-lāh remet a l'emir l'any 850-851, on decideix prescindir de bona part dels guerrers enviats des de Còrdova amb ordres de romandre amb ell, ara que la frontera era en pau i que l'enemic estava dividit. Aquí el governador argüia que en tenia prou amb cent trenta joves, entre clients i servidors de la seva confiança, tot i que retenia un grup de genets de la guàrdia personal de l'emir que havia enviat a reforçar les guarnicions de la costa. És el mateix governador de Tortosa qui aleshores gestiona els ingressos de capitació dels protegits, el delme de les collites i la resta d'impostos, tant per finançar despeses i tropes, com per reparar i reforçar les defenses o el rescat de presoners ${ }^{9}$.

Més enllà de suggerir una escassa islamització d'aquestes societats de frontera, avui l'arqueologia també aporta indicis que permeten identificar les invisibles defenses de l'enemic a vèncer, aquelles que durant tot el segle IX impediren l'avenç carolingi més enllà del riu Llobregat. Aquest és el cas de les torres de guaita de planta circular, un tipus de fortificació habitual i origen controvertit, representat com és per centenars d'exemples molt diversificats

\footnotetext{
${ }^{6}$ Benet 1982; Martí, Colomer 2011.

${ }^{7}$ Molist, Bosch 2012.

${ }^{8}$ Bramon 2000,pp. 144-145.

${ }^{9}$ Ballestín 1999, pp. 72-74; Bramon 2000, pp. 205-206.
} 
al conjunt de Catalunya i que sovint constitueixen l'element primitiu o principal de nombrosos castells. L'interès científic per aquesta mena d'edificis es remunta dècades enrere, quan s'impulsà el seu estudi i s'elaboraren unes primeres propostes tipològiques sobre les fortificacions altmedievals, tot suggerint que correspondrien exclusivament a l'època comtal, malgrat que a terres de Lleida s'observava que alguns casos podien remuntar-se al període andalusí. Recentment també a Catalunya Vella ha estat identificada tota una xarxa d'aquestes torres de vigilància que cal datar en ple segle VIII, integrada per una dotzena casos que reben la denominació específica de "far" (pharus) i que enllacen els Pirineus amb la ciutat de Barcelona, alguns exemples dels quals fins aquí s'atribuïen a l'època romana per l'ús d'aparell d'opus quadratum i encoixinat ${ }^{10}$.

Malgrat la seva importància simbòlica i estratègica, aquesta xarxa de fars gairebé no traspassa el riu Llobregat i, més enllà, pel seu aparell només s'hi poden assimilar la torre del Castellvell de Rosanes i la torre de Les Gunyoles (Avinyonet del Penedès), que no reben aquella denominació estricta. En aquestes comarques, però, són nombroses les torres de guaita que presenten característiques arcaïtzants i diverses solucions constructives. Així s'observa en relació a certes torres de planta oblonga de la frontera del comtat de Barcelona, tot i que s'atribueixen als inicis de l'ocupació comtal. Aquí comptem no menys de sis casos d'aquest tipus, com són el castell de Font-rubí, Can Pascol (Castellví de la Marca), ipso Moro o El Papiol (L'Arboç), la Talaia de Calafell, Montferri o el castell de Vila-rodona. Tots ells integren un dispositiu de vigilància, en connexió visual, que enllaça la riba dreta del riu Llobregat amb la ciutat de Tarragona, on les talaies de Castellvell de Rosanes, Fontrubí, Castellvell de la Marca i Montferri constitueixen la columna vertebral d'un veritable sistema, mentre que altres torres similars resulten subsidiàries i se situen més a prop dels llocs habitats i del pla. Són dades incipients que corroboren la importància que aleshores encara mantenen el Camp i la ciutat de Tarragona ${ }^{11}$.

Gairebé mancats de dades arqueològiques precises, comencem per anotar que al cim del Castellvell de Rosanes velles excavacions detectaren ceràmica romana residual i un enterrament en tegulae a prop de la torre, indicis que entre d'altres arguments portaren a datar aquest edifici en època antiga. Avui s'observa, però, que no existeix garantia arqueològica d'això i es detalla la seqüència evolutiva del conjunt fortificat a partir de l'estudi de paraments. Sobre el cim, a la torre circular en època preromànica s'hi adossa una altra

${ }^{10}$ Riu 1985-1986; Fité 1986; Martí (ed.) 2008.

${ }^{11}$ Gibert 2006; Bolòs 2000; Gonzalo 2011. 
torre allargassada d'angles arrodonits, caracteritzada pel recurs de l'opus spicatum, i s'observen obres similars al mur perimetral que circumda la mola superior del castell ${ }^{12}$.

En correspondència amb el seu homònim del Baix Llobregat al Castellvell de la Marca els treballs arqueològics en curs també reporten materials romans i andalusins, entre d'altres fases d'ocupació, tot i que les característiques constructives de la seva torre de guaita són preromàniques. I encara cal afegir que el registre material de la torre oblonga de Montferri correspon exclusivament a l'etapa precomtal, com observem en prospecció a la comarca de l'Alt Camp. Amb l'ús predominant de l'obra de maçoneria i el recurs habitual de l'opus spicatum, moltes altres torres de planta circular de les comarques ponentines del comtat de Barcelona haurien precedit la conquesta comtal i potser són majoria en aquesta zona. És una hipòtesi comprovada al cas segarrenc de Vallferosa (Torà), un magnífic exemplar que integra dos edificis concèntrics i on s'obtenen datacions absolutes en ple segle IX, quan el sector encara depenia d'al-Andalus ${ }^{13}$. Malgrat que les dades arqueològiques disponibles són incipients encara, no dubtem que cal preveure un fructífer desenvolupament d'aquesta línia de treball en un futur immediat, sempre i quan l'anàlisi es condueixi de forma metòdica $\mathrm{i}$ amb perspectives àmplies, atès que no són construccions isolades sinó que constitueixen dispositius complexos.

Al seu torn, l'ocupació comtal es tradueix en l'establiment de desenes de castells termenats que apleguen velles i noves fortificacions, nous districtes castrals (castra) que a les comarques ponentines del Llobregat basteixen una malla molt densa que no deixa intersticis sense control. Un cop resolt que no són una innovació del segle $\mathrm{X}$ sinó que tenen precedents islàmics, les torres de planta circular encara constitueixen un dels principals components defensius a l'època comtal, tant als enclavaments castrals com als dominis alodials, com es comprova aleshores al Bages, on alguns exemplars disposen d'un mur o cortina que defineix un reduït recinte annex. En molts d'aquests casos la iniciativa pot atribuir-se a un personatge concret, que fixa aquí la seva residència i que n'assumeix la propietat o la gestió, especialment durant les primeres fases del procés ${ }^{14}$.

Contra aquest model de fortificació simplificada cal contraposar, però, la complexitat que assoleixen els castells de la Marca del comtat de Barcelona durant el segle $\mathrm{X}$, on les primeres construccions ofereixen tot un ampli repertori de recursos i de solucions tècniques ${ }^{15}$. Certs exemples excavats com

\footnotetext{
12 Bolòs, Pagès 1986; Mauri 2006, pp. 206-208; Mauri 2014.

${ }^{13}$ Gonzalo, Martí 2015; Menchón 2011.

${ }^{14}$ Gibert 2011,pp. 405-500.

${ }^{15}$ Mauri 2006, pp. 200-229.
} 
els castells de Gelida, Subirats i Mediona, entre d'altres, provarien que les fortificacions principals ara són torrasses o edificis residencials amb diversos pisos d'alçada, construccions adaptades a la topografia de cada lloc. Completen la fortificació altres baluards polimorfs, així com murs perimetrals i valls que defineixen amplis espais oberts a l'interior del castell. Són conjunts amb una especialització militar ben definida que no cerquen tant la comunicació de llarga distància com el control absolut de la xarxa viària, amb l'ocupació dels passos sensibles. De fet, constitueixen l'escenari idoni on l'exèrcit comtal ara es multiplica i són el lloc de provisió principal que a partir d'aquí genera una cavalleria estable i ben equipada.

En l'establiment del dispositiu castral de la Marca de Barcelona hi jugaria un paper fonamental la figura del veguer (vicarius), una nova funció que no es documenta fins aquestes dates a les fronteres dels comtats catalans. En origen, la demarcació de la vegueria (vicaria) i el càrrec de veguer són institucions carolíngies, amb un grau d'implantació regional molt desigual durant el segle IX. Concebuda com una subdivisió del comtat, la vegueria carolíngia és ben present al nucli de l'imperi i també al cor del regne d'Aquitània, així com al Massís Central, sovint en concurrència amb altres tipus de demarcacions o institucions locals. Centres secundaris de poder territorial, les vegueries imperials poden ser alhora pols eclesiàstics i econòmics o seus judicials i militars que arriben a tenir una dilatada pervivència en el món postcarolingi, ara adaptades a noves circumstàncies, així com el veguer abandona la condició d'agent públic per esdevenir senyor de la circumscripció ${ }^{16}$. Particularment, a la diòcesi septimana de Besiers la introducció de la vegueria no sembla produir-se abans de mitjan segle X, aquí aplicada a la reordenació de l'espai diocesà septentrional i assignada a un reduit nombre de fortificacions ${ }^{17}$.

Als arxius catalans no es documenten vegueries carolíngies i el concepte de veguer només es concreta d'ençà del segon terç del segle $\mathrm{X}$, aquí concebut com un càrrec de representació del comte en certs districtes castrals ${ }^{18}$. Així, tot i que la pròpia documentació sovint silencia la condició vicarial d'aquests actors, la noció de veguer correspon aleshores a l'exercici d'una funció delegada i, principalment, guarda relació amb certs castells termenats dels comtats de Barcelona, Osona i Manresa, on els drets de conquesta derivats de l'expansió comtal són inqüestionables. També és cert, però, que aquest càrrec inicialment només s'assigna a un selecte i reduït grup de magnats que

\footnotetext{
${ }^{16}$ Hautefeuille 2009; Lauranson-Rosaz 2009.

${ }^{17}$ Schneider 2007.

${ }^{18}$ Bonnassie 1975-1976, pp. 173-177.
} 
acumulen nombrosos béns alodials, també fora de la demarcació castral que teòricament els seria assignada. Ells són al bell mig del desplegament dels dispositius de defensa i de la construcció de noves fortificacions, això sí, en nom del comte, que és qui els faculta.

Va ser una tasca complexa que requerí d'un finançament idoni i, per això, de bon començament la construcció de castra hauria comptat amb els serveis dels habitants dels districtes, així com s'assignaren a la seva gestió els rèdits eclesiàstics de les demarcacions respectives i molt especialment el cens de la dècima, que el comte considera un recurs propi. Per tal de legitimar aquests drets, hom pot comprendre que durant el tercer quart del segle $\mathrm{X}$ els comtes promoguin diversos intents infructuosos de restauració de l'arquebisbat de Tarragona amb la reiterada proclamació de nous arquebisbes, iniciatives que impliquen greus enfrontaments entre les famílies comtals, una problemàtica que depassa l'estricta lectura d'aquests fets en clau d'independència eclesiàstica ${ }^{19}$. Així mateix, el comte Sunyer i els seus descendents aviat alienaren la propietat alodial de nombrosos castells mitjançant concessions, vendes o permutes entre els seus col-laboradors, transaccions que no afecten només les fortificacions, sinó que també incorporen habitualment les esglésies corresponents i els seus rèdits. És, però, durant el segon quart del segle XI que les mencions de veguers comtals es rarifiquen, quan la privatització generalitzada dels castells deriva finalment en l'extinció d'aquesta figura estricta, tot i que el mot encara persisteix amb el significat de custodi o castlà i, més tard, de delegat comtal en certes viles i demarcacions.

És al context inicial de conquesta i ocupació de la Marca del comtat de Barcelona on participa activament el veguer Sendred, ancestre inequívoc del llinatge. És ell qui posseeix la custòdia del Castellvell de Rosanes, situat sobre el congost de Martorell i el pas de la Via Augusta, principal porta d'accés a la ciutat de Barcelona i, també, cap de pont sobre el qual s'articula la conquesta o el domini de la Marca. Ignorem, però, quan les forces de Barcelona prengueren definitivament una posició estratègica que hom degué disputar aferrissadament durant tot el segle IX, abans que arribessin els comtes cerdans.

${ }^{19}$ Martí 1994; Jarret 2010. 


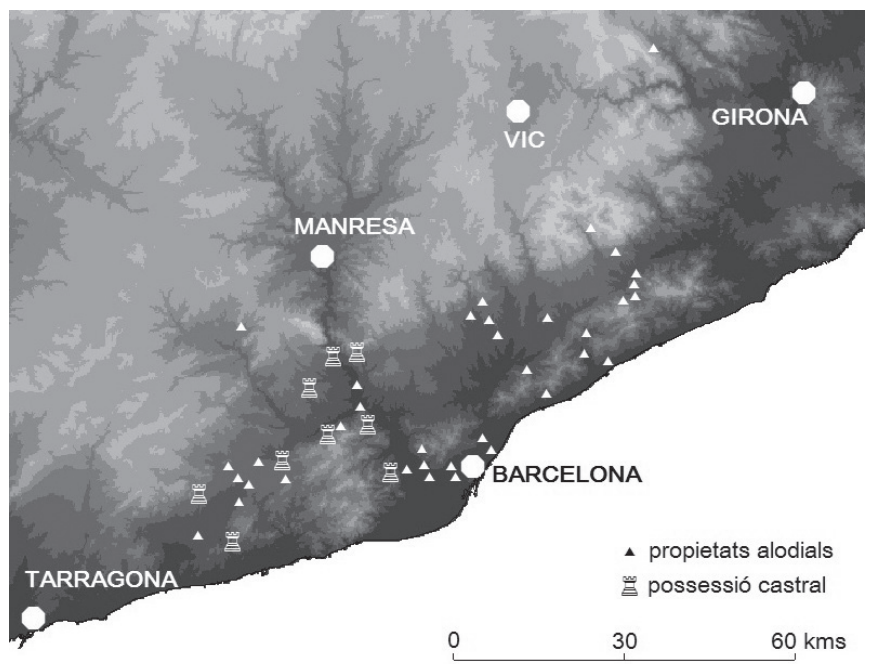

Fig. 2. Fortificacions i propietats dels Castellvell durant el segle X.

\section{El VEGUER SENDRED, MEMBRE D'UN LLINATGE ARISTOCRÀTIC BARCELONí}

Les actes que protagonitza el veguer Sendred a la documentació llatina es redueixen bàsicament a dues compravendes datades entre els anys $938 \mathrm{i}$ 951, amb valuoses informacions sobre el nucli del patrimoni familiar, mentre que altres notícies completen el seu perfil. És garantit que procedeix de la ciutat de Barcelona, que ocupa un lloc primordial a la Marca del comtat i que establí relacions de parentiu aristocràtiques adients amb la seva rellevància regional. Amb moltes reserves, però, sobre la seva ascendència suposem que Sendred podria ser fill de Sendred i nét d'Isembard, notables personatges del seu temps.

Molt probablement els pares o els avis de Sendred guarden una certa relació amb les comarques gironines, com deduïm d'una notícia de la fi del segle X, on Ènnec i Amat, que serien els seus néts o besnéts, donen al monestir de Sant Pere de Casserres una terra amb dècimes i primícies o altres drets que posseïen a Sant Cristòfor de les Planes d'Hostoles, l'única propietat familiar que coneixem fora dels límits del comtat de Barcelona. Això ens porta a relacionar-los amb els esposos Sendred i Emma, filla de Sisegod, que mantingueren relacions preferents amb la comtessa vídua Garsenda. Així i amb el consentiment de Sendred, l'any 919 Emma venia a la comtessa certs drets en la vall de Llagostera, on son pare havia obtingut un precepte reial. Igualment, el seu espòs revenia a la comtessa en 921 altres propietats que abans li havia 
comprat, situades a la Vall d'Aro i al Vallès ${ }^{20}$. Anotem encara que la concessió d'aquell precepte se situaria vers l'any 891, quan també n'obtenen la Seu de Girona, el vescomte Petroni i Guifré, nét del vescomte Esteve de Narbona i fill dels comtes Delà i Quintol de Girona ${ }^{21}$. Fins i tot l'àvia paterna del veguer també disposaria d'altres béns a prop de la Vall d'Hostoles, si identifiquem aquesta amb Iquila, que l'any 894 venia a son fill Sendred l'alou besaluenc de Terruç amb el consentiment d'Isembard, que seria el seu espòs. De fet, bé podria ser el mateix missus Isembard que reiteradament representà els bel-licosos marquesos Humfrid i Bernat de Gòtia a Narbona i al Rosselló, documentat entre els anys $859-901^{22}$.

L'onomàstica dels tres fills del veguer Sendred també avalaria una certa ascendència aristocràtica difosa entre Girona, Narbona i Barcelona, o evocaria relacions amb alguns magnats contemporanis, vescomtes principalment. Com molts altres, aleshores tots tres germans reben un nom i un renom o sobrenom, un doble apel-latiu que hom pot emprar de forma dual o individuada als documents. De fet, el nom d'Onofre o Unifred Amat tant pot recordar els vescomtes conflentins Unifred i Unifred Falquet, l'un documentat d'ençà de l'any 913 i l'altre desposseït per traïció abans de 952, com el marquès Humfrid del segle anterior, mentre que el renom Amat comptaria amb parents gironins ${ }^{23}$. Així mateix, Ènnec Bonfill comparteix el sobrenom del bisbe Miró de Girona i l'apel-latiu de diferents vescomtes d'aquesta diòcesi durant el segle $X$, entre els quals un si més no que actua als comtats de Girona i Besalú entre els anys 917-951, a més del vescomte de Besalú Ènnec Bosó, explícit entre els anys 959-966, i un altre vescomte homònim documentat a Empúries vers 959-965 $5^{24}$. Només el cas de Sendred Màger no disposa de referents vescomtals coneguts ni denota influències precises, atès que combina el popular nom got del pare amb un altre que també és freqüent. Tot i els indicis aportats, hem de remarcar finalment que no podem garantir que Isembard i Iquila o Sendred i Emma siguin efectivament els avis i els pares de Sendred de Castellvell.

Tampoc disposaríem de precisions familiars sobre l'esposa del veguer Sendred, Truitel·la, de qui només tenim notícia certa que era morta l'any 988. Malgrat tot, podria ser aquella mateixa que en 951 compartia amb Oliba

\footnotetext{
${ }^{20}$ Llop 2009, doc. 134; Sobrequés, et al. 2003, docs. 162 i 173.

${ }^{21}$ Sobrequés, et al. 2003, docs. 53, 63, 78 i 255; Abadal 1926-1950, pp. 365-367; Roura 1985-1986, pp. 71-72; Martí 1997, doc. 24.

${ }^{22}$ Sobrequés, et al. 2003, doc. 88; Abadal 1926-1950, pp. 341 i 353; Ponsich 2006, docs. 92 i 97.

${ }^{23}$ Ordeig 1999, docs. 119-120 i 1195; Sobrequés, et al. 2003, doc. 196; Abadal 1926-1950, pp. 391-392.

${ }^{24}$ Sobrequés, et al. 2003, docs. 154, 171-172, 183, 199, 270, 279, 281, 288, 295, 334-335, $363,374,378$ i 518.
} 
i Iquila la propietat d'una vinya veïna d'una altra del veguer a Castellvell de la Marca. Sense proves explícites que ho garanteixin, deduïm que aquests tres personatges poden ser germans i que Oliba és el pare del bisbe Vives de Barcelona, qui exercirà aquest càrrec entre els anys 974-995 i que considerem nebot del veguer ${ }^{25}$.

En qualsevol cas, descartem que Sendred sigui descendent directe de la família comtal, tal i com proposava Benet a partir del Muqtabis $V$, la font que millor descriu les competències extraordinàries que aquest veguer posseí als territoris de la Marca. En l'àmplia i detallada narració d'Ibn Hayyān, és a les treves subsegüents a la conquesta comtal on Sendred manifesta la seva importància política, una llarga descripció que resulta proporcionada en relació a l'amplitud i als efectes duradors que van tenir les paus en aquest sector de la Mediterrània i de la Marca Superior d'al-Andalus. Així, l'any 940 el secretari del califa i el comte Sunyer assolien a Barcelona un primer acord, amb l'adhesió d'Hug d'Arlès, de la vescomtessa Riquilda de Narbona i d'altres magnats, un pacte que va estendre la treva de la frontera del comtat d'Urgell fins la Provença. En setembre d'aquell any és l'abat Gotmar de Sant Cugat del Vallès, futur bisbe de Girona, qui a Còrdova representa els comtes Sunyer de Barcelona i Sunifred d'Urgell o els fills d'ambdós, tot i que el segon no tingué descendència masculina. En maig de 941 és el propi Sendred qui viatja a Còrdova com a missatger de Sunyer de Barcelona i (del) fill del seu oncle patern per tal de renovar el pacte, un passatge on es podria dubtar si l'ambaixador és nebot del comte o si representa un nebot comtal. Vers la fi d'aquest mateix any és el califa qui envia un missatge adreçat a Sunyer, Aŷnād ibn al-Mundir, l'abat Gotmar, Sendred i altres francs del pacte ${ }^{26}$.

Observem que la narració només altera les referències al comte Sunifred d'Urgell i res impedeix que aquest hagi mort entre la primera i la segona ambaixada cordovesa. Així i encara que de forma injustificada es tendeix a prolongar fins l'any 948 el seu govern, comprovem que la darrera notícia certa del comte Sunifred a la documentació llatina és de l'any 935 i que el mes de maig de 941 la comtessa Adelaida d'Urgell actua sola ${ }^{27}$. Desaparegut Sunifred, aleshores l'hauria succeït en el càrrec son nebot Ermengol, fill del comte Sunyer, a qui correspondrien les equívoques al-lusions d'un nebot comtal i d'Aŷnād ibn al-Mundir, que hauria governat el districte durant els anys 941-942 i que precedí son germà Borrell. Podem descartar, en conclusió, que Sendred sigui nebot del comte Sunyer.

\footnotetext{
${ }^{25}$ Fàbrega 1995, doc. 178; Baiges, Feliu, Salrach (dirs.) 2010, doc. 8; Feliu 1984.

${ }^{26}$ Benet 1983, pp. 83-84; Bramon 2000, pp. 292-300.

${ }^{27}$ Baraut 1979, doc. 100.
} 
D'altra banda, el perfil de la família del veguer és el d'una nissaga ben arrelada a la ciutat de Barcelona, amb nombroses propietats arreu del comtat i capaç d'oferir als seus membres una certa formació, ateses les seves signatures autògrafes als documents de l'època. Aquest és el cas, per exemple, d'una primera notícia que pensem identificar l'any 928, quan Sendred subscriuria el document de venda del vescomte Lleopard a son fill Otger del castell d'Eramprunyà. La seva presència entre el seguici vescomtal sembla garantida si hom considera que Onofre Amat, fill de Sendred, prendria per esposa Riquilda, filla d'Otger, membres d'una família que reclama certes precisions. De fet, aquesta és l'única notícia explícita del vescomte Lleopard de Barcelona, tot i que ell i Otger han estat considerats vescomtes de Girona. Ha de ser el mateix Lleopard, però, que l'any 936 subscrivia en primer lloc dues transaccions entre el bisbe Radulf d'Urgell i son fill Oliba amb els comtes Sunyer i Ermengol, dues actes que semblen redactades a $\mathrm{Vic}^{28}$.

Fill de Lleopard i documentat amb el càrrec de vescomte entre els anys 945-959, l'únic testimoni que avalaria l'adscripció gironina d'Otger és una donació comtal que hom degué redactar a la ciutat de Barcelona, així com un altre document similar expedit pocs dies abans. Hom desconeix cap propietat seva a Girona i sabem que posseïa terres al terme osonenc de Seva, vers Vall-llossera, tot i que és al comtat de Barcelona on el vescomte Otger concentra la seva activitat i el seu patrimoni. Així i encara que no expliciti el seu càrrec, considerem que són seves les subscripcions autògrafes de dues donacions a la Seu dels anys 951 i 959, una de la comtessa Riquilda i una altra de béns particulars situats a l'extrem de la Marca. Amb diverses propietats testimoniades a terres de Barcelona, Otger hauria mort poc abans de 962, quan es documenta una vinya de la que fou propietari a Vilapicina i que més tard posseí la Seu de Vic, mentre que en 968 el monestir de Sant Pol de Mar evocava la seva donació de l'alou vallesà de Corró. Encara el recorden altres documents posteriors que esmenten propietats als llocs sabadellencs de Jonqueres i Sobarbar o al Vallès ${ }^{29}$. Desaparegut sense descendència masculina, la successió d'Otger al castell d'Eramprunyà planteja certs problemes, atès que a partir d'ara serà Galí de Les Gunyoles qui ocupi una posició hegemònica en aquest terme castral, on fundà el monestir de Santa Maria de Castelldefels. Potser germà d'Otger, al seu propi testament Galí disposava l'any 981 de nombroses propietats als comtats de Barcelona, Manresa i Osona, amb terres també al terme de Seva. En qualsevol cas, finalment fou el comte Borrell qui

${ }^{28}$ Udina 1951, doc. 91; Coll 1988-89; Ordeig 1999, docs. 419-420.

${ }^{29}$ Sobrequés, et al. 2003, doc. 265; Fàbrega 1995, docs. 30, 43, 54 i 67; Ordeig 1999, doc. 700; Baucells, et al. 2006, doc. 39; Abadal 1926-1950, pp. 202-204; Puig 1995, docs. 43, 51 i 205; Junyent 1980-1996, doc. 649. 
recuperà la titularitat del castell d'Eramprunyà i l'any 988 el bescanviava a la seva esposa per l'alou urgellenc de Tuixent ${ }^{30}$.

De retorn a la figura de Sendred, cal remarcar que el primer document on ell mateix és subjecte principal correspon a l'any 938, quan comprava per cent sous als esposos Salomó i Vigília i als seus fills la meitat de dos molins que aquell havia edificat al riu Anoia, al terme del Castellvell de Rosanes i a prop de Martorell ${ }^{31}$. Si considerem que aleshores als senyors jurisdiccionals habitualment els pertoca la titularitat d'una fracció d'aquest tipus d'instal-lacions, cal creure que aquesta compra completa el seu dret preeminent i certifica el domini de Sendred sobre Castellvell. L'escrivà fou el clergue i levita Gregori, autor d'altres documents relatius a Barcelona i Girona entre els anys 924-945.

Ateses les seves relacions, també pensem que cal identificar amb el senyor de Castellvell aquell Sendred que consta després dels comtes Sunyer i Riquilda a l'acta de consagració i dotació de l'església del monestir de Sant Pere de les Puelles de Barcelona l'any 945, tot precedint Oliba, Agela i el comte Borrell. Remarquem que les formes Agela i Abila corresponen a un mateix nom, com proven altres exemples, i que cal identificar aquest personatge amb el futur bisbe Vives de Barcelona, levita i escrivà aleshores, aquí en companyia de son pare Oliba i de qui considerem el seu oncle ${ }^{32}$.

És més revelador el segon document patrimonial de l'any 951, on el veguer Sendred ven per mil sous a son fill Onofre Amat unes cases que posseeix a Barcelona i diverses terres situades a diferents llocs. Cal destacar que les cases de la ciutat (casas et solarios et curte) eren heretades dels pares i que es trobaven a prop d'altres propietats dels seus senyors, entre la via de les torres del comte Miró i un casal del difunt comte Sunyer. Als confins entre els barris actuals de Pedralbes i Les Corts, en Bederrida deixava triar a son fill aquelles 30 mujades de vinya que preferís, fossin heretades de son pare o adquirides per compra. Eren fruit de compres, però, el camp amb cases, horts, prats i illes que cedia en Abrera (Breda), un extens alou que limitava amb els rius Llobregat i Anoia o amb el torrent de Llops (Martorell). El text no precisa, però, com adquirí la vinea maiore de Castellvell de la Marca, situada subtus ipso bugho, entre els camins de Canyelles i Llorenç, referents que ens situen vers Sant Marçal del Penedès ${ }^{33}$.

I aquestes són, de fet, les poques notícies certes que identifiquem en vida del veguer, tot i que d'alguns textos posteriors se'n desprenen informa-

\footnotetext{
${ }^{30}$ Rius 1945-1947, doc. 136; Junyent 1980-1996, doc. 537.

${ }^{31}$ Baiges, Feliu, Salrach (dirs.) 2010, doc. 6.

32 Ordeig 1993-2001, doc. 57; Ordeig 1999, doc. 45; Fàbrega 1995, docs. 44-45, 57 i 65.

${ }^{33}$ Baiges, Feliu, Salrach (dirs.) 2010, doc. 8.
} 
cions personals o patrimonials d'interès. Aquest és el cas del Castellvell de la Marca, que constituirà un dels principals baluards del patrimoni familiar i que, fins i tot, consta que hauria estat adquirit pel propi Sendred, d'acord amb un document problemàtic que ha portat de corcoll els investigadors. Procedent dels arxius episcopals, és un trasllat datat en 1196 de l'acta de venda d'aquest castell atorgada pels germans Calabuig i el prevere Guadamir al seu senyor Sendred, un document que presenta una datació insòlita que hom tendeix a reduir vers l'any $990^{34}$. Per les incongruències que comporta, considerem que cal desconfiar d'una falsificació que amplia els límits occidentals del terme de Castellvell fins la comarca de l'Alt Camp.

Procedent de l'arxiu comtal, semblaria més creïble la restitució elaborada l'any 1026 d'una permuta on el comte Sunyer hauria concedit als mateixos germans Calabuig i Guadamir el Castellvell de la Marca a canvi del castell de La Guàrdia de Montserrat, una transacció datada vers 936-93735. Aquest text, però, no pretén recuperar literalment el document original sinó que només refereix certes dades, com un terme reduït als confins amb la franquesa d'Olèrdola i els castells de Castellet, Banyeres o Marmellar. Així mateix, l'autoria s'atribueix al prevere i escrivà Taurell (913-959) i s'afirma que el bisbe Guilarà de Barcelona (937-959) en seria testimoni, així com altres dos enigmàtics personatges de nom Gausfred, un dels quals seria fill de la gironina Adalgarda, mentre que l'altre ho seria del comte Sunyer. Si el bisbe i l'escrivà són congruents amb la data proposada, resulta més problemàtica la identificació certa d'uns magnats que grinyolen força entre les dades conegudes, sense correspondència aleshores a Girona ni entre la família comtal. Considerem, en consequiència, que una ombra de sospita plana també sobre aquesta permuta.

Si més no, és cert que el prevere Guadamir i els seus germans Llunès i Calabuig vengueren al comte Sunyer certs béns situats al castell de La Guàrdia o de Bonifaci, com afirmen algunes notícies que cal prendre també amb molta cautela, atès que pertanyen al fons inicial del monestir de Montserrat, on les falsificacions proliferen. Atribuïdes a l'any 931, per la seva precocitat poca confiança ens mereixen tres vendes successives on els germans transfereixen al comte nombrosos béns situats a Collbató (Collo Albedoni) i Almedovar. Més creïble resulta en 945 la venda del puig d'Andaleco, que hom situa en aquests llocs i que protagonitzen els mateixos actors. Llunès encara reapareix l'any 954 en relació a La Guàrdia i Calabuig consta una dècada després referit a Esparreguera i a Castellar del Vallès, on també posseí terres ${ }^{36}$. Mort l'any

\footnotetext{
${ }^{34}$ Fàbrega 1995, doc. 204.

${ }^{35}$ Feliu, Salrach (dirs.) 1999, doc. 175.

${ }^{36}$ Altés 1994, docs. 2, 13, 28 i 45; Puig 1995, docs. 20 i 65.
} 
964, després veurem que el prevere Guadamir avala la identificació d'aquest grup amb la família del veguer Sal·la.

Tot $i$ els problemes que s'observen en interpretar unes i altres referències, al capdavall cal destacar que és a Calabuig i als seus germans que s'atribueix inequívocament la possessió del castell de La Guàrdia, primer, i de Castellvell de la Marca, després. Sense proves fiables sobre la incorporació del darrer domini al patrimoni dels veguers de Castellvell, avancem també que pot haver estat mitjançant un matrimoni durant la següent generació.

El cas és que més enllà de l'any 951 Sendred no torna a documentarse amb certesa, malgrat que encara podria haver estat ell mateix l'emissari que el comte Miró de Barcelona envià a Còrdova l'any 953. D'acord amb el silenci de les fonts i la successió immediata dels seus fills, cal suposar que hauria mort poc després, previsiblement abans d'assolir seixanta anys. Malgrat tot, fins aquí no hi ha dubte que aquest veguer havia ocupat un rol principal a la conquesta i ocupació de la Marca del comtat i a la reorganització militar d'aquesta zona. Així es recorda en consagrar l'església penedesenca del castell d'Avinyó vers l'any 992, on es detalla que el veguer Sendred la posseí per aprisió $^{37}$. Correctament identificada la descendència de Sendred, avui també es perfila l'origen aristocràtic de les seves nores, que no desmereixen gens l'àmplia dimensió política d'aquest personatge.

\section{L'HEREU ONOFRE AMAT, EL VEGUER ÈNNEC BONFILLL I L'ALTRE GERMÀ, SENDRED MÀGER}

Tot indica que Onofre Amat fou el primogènit dels tres fills. Ell és el principal beneficiari del patrimoni patern i qui hauria renovat els nexes familiars amb els vescomtes de Barcelona d'aquell temps, atès que estava casat amb Riquilda, molt probablement filla del vescomte Otger. D'ella sabem que l'any 997 posseïa un hort al Raval de Barcelona i que en 1002 tenia una vinya al Clot. Un cop morta, l'any 1008 encara torna a documentar-se aquesta mateixa vinya que havia estat del vescomte ${ }^{38}$. En tot cas, cal remarcar que no existeixen proves directes que ella sigui l'esposa d'Onofre Amat, tot i que sembla confirmar-ho el nom d'un dels fills de la parella, Otger de Castellet.

Onofre Amat és a terres del Penedès on verifica les seves principals activitats patrimonials i aquí entre els anys 956-990 disposa de nombroses propietats als confins del castell d'Olèrdola, amb terres als llocs de l'Aranyó,

${ }^{37}$ Bramon 2000, pp. 312-313; Ordeig 1993-2001, doc. 109.

${ }^{38}$ Fàbrega 1995, doc. 310; Baucells, et al. 2006, docs. 27 i 100-101. 
la Calçada i Llitrà (Vilafranca del Penedès) o també a La Granada i Les Gunyoles, a més de comprar l'any 977 al comte Borrell el castell de Sant Esteve de Castellet per seixanta pensas, lliures d'argent possiblement, i de posseir vinyes a Premià, al Maresme ${ }^{39}$. Més endavant, durant els anys 986-996 actua com a testimoni d'algunes transaccions dels comtes Borrell i Ramon Borrell o en certs actes judicials, puntualment en companyia de son germà Ènnec Bonfill, i cal datar poc més tard de l'any 996 la seva darrera notícia, quan tots dos donen a Sant Pere de Casserres aquells drets de les Planes d'Hostoles que potser els pervenien dels avis ${ }^{40}$.

Que Onofre Amat és el principal beneficiari del patrimoni del veguer Sendred no ofereix cap mena de dubte, tal i com l'any 951 comprava a son pare diversos béns situats a la ciutat de Barcelona i a la meitat occidental del comtat. De fet, l'herència rebuda hauria estat molt més àmplia si hem de creure un document atribuït al mateix autor de la venda paterna, el prevere Salomó, on Onofre heretaria son fill Guillem tot seguint un procediment original, el d'atorgar una donació al fidel Seniol que, al seu torn, donava els béns rebuts al seu fillol i fill de son senyor i de Riquilda l'any $978^{41}$. En aquest cas, però, els alous transferits es troben preferentment al Vallès Oriental, malgrat que també s'afegeixen els d'Esplugues i Bederrida, pròxims a la ciutat. Així, al Vallès hom relaciona els casos de Gallecs (Mollet del Vallès), Granollers, Campsentelles, amb (apud) la seva parròquia i els seus drets, Vilardell, amb la seva parròquia i els seus drets, Viladebocs i Olzinelles (Sant Celoni), Montseny, villa Viviano anomenada Mosqueroles (Fogars de Montclús) i també al Maresme. Una ombra de sospita plana, però, sobre l'autenticitat d'aquest document, un text que l'editor adverteix que no és original sinó una imitació i del que també es conserva una còpia coetània datada l'any 1016, quan considerem més probable que hagi estat redactat. Desconeixem els motius que l'induïren, tot i que intuïm que lesionava els drets del germà de Guillem, Otger de Castellet.

Casat amb Gerosolima, identifiquem Seniol amb certesa entre els anys 977-995, quan és propietari de terres a diferents llocs del comtat de Barcelona, com Bederrida o Terrers Blancs, Palau-solità o Palou (Granollers), i quan manté relacions habituals amb el comte Borrell, qui l'esmenta entre els nobles del seu palau. Fill potser d'un altre Oliba, aquest fidel i padrí Seniol seria germà d'Anna i hauria mort vers l'any 998, quan un acord o pacificació judicial ens informa que havia estat tutor dels seus nebots Otger i Longobard

\footnotetext{
${ }^{39}$ Rius 1945-1947, docs. 45, 126 i 259; Fàbrega 1995, docs. 83, 113, 125, 126 i 148.

${ }^{40}$ Fàbrega 1995, docs. 160 i 168; Rius 1945-1947, docs. 190, 314 i 317; Ordeig 1999, doc. 1736; Llop 2009, doc. 134.

${ }^{41}$ Udina 1951, doc. 182.
} 
durant la minoritat d'aquests. Fills orfes de Delà, la tutela de Seniol es valora aleshores del tot deficient, atès que l'acusen d'haver-los gairebé abandonat entre els seus parents (in medio propinquum ac consanguinuum), on no trobaren qui els ajudés. Contràriament, els mateixos tutelats agraeixen el comportament del seu padrastre Geribert, qui generosament els acollí, els vestí adequadament, els armà i els donà cavalls per tal que servissin i militessin al palau del comte, tot i que alienés alguna propietat dels seus pupils al veguer Geribert de Subirats, fill del vescomte Guitard ${ }^{42}$.

Malgrat que aquest no és lloc d'entretenir-nos amb la figura de Delà, germà de Naví, anotem que havia estat casat primer amb Anna i després amb Eiga, que sembla haver mort poc abans de l'any 983 i que deixà altres fills, com el monjo Eldemar de Sant Cugat, Ricard i també Adelaida. La seva és una família d'importants propietaris amb forta presència al Vallès i a la Marca, on el seu nom s'associa al d'una torre que posseí (turre de Delane), situada al lloc on després s'establí la vila de Vilafranca del Penedès. Només puntualment, però, s'empra el doble apel-latiu de Vives Otger per referir-se a un dels darrers fills de Delà, una duplicitat que s'afegeix als indicis que relacionen les famílies del bisbe Vives i els Castellvell ${ }^{43}$.

$\mathrm{Al}$ seu torn, Ènnec Bonfill fou el fill del veguer Sendred que adquirí major fortuna i qui va mantenir la confiança preferent dels comtes, als quals representa assíduament. Present en desenes de documents datats entre els anys 963-1003, Ènnec fou també un oportunista que aprofità la seva privilegiada posició per invertir en l'adquisició de tota mena de drets rústecs i castrals, on mobilitza i acumula una veritable fortuna.

Com el cas d'Onofre, el matrimoni d'Ènnec és igualment un enllaç aristocràtic i la seva esposa Eiga era filla del vescomte Isarn de Conflent, una filiació que expliciten diversos documents. El castell de Gelida constituí el seu domini principal (Bonifilius gelitensis), on Eiga encara residia quan el bisbe Sal·la d'Urgell, son germà, hi vingué a morir l'any 1010, en tornar de l'expedició de Còrdova, i no tenim constància de la mort d'aquella fins l'any $1016^{44}$.

Les relacions preferents d'Ènnec Bonfill amb la casa comtal es documenten d'ençà de l'any 963, en temps de Miró de Barcelona, quan comprava al comte el castell penedesenc de Masquefa amb la seva parròquia, a més de l'alou de Mata al Maresme ${ }^{45}$. Aleshores Guitard ja seria vescomte, tot i que

\footnotetext{
${ }^{42}$ Rius 1945-1947, docs. 126, 233-234, 295 i 302; Fàbrega 1995, docs. 190, 192-193, 201, 253, 312 i 329; Baucells, et al. 2006, doc. 40.

${ }^{43}$ Rius 1945-1947, docs. 233-234; Baucells, et al. 2006, docs. 9, 184 i 1693; Muntaner 2012.

${ }^{44}$ Miquel 2001; Fàbrega 1995, docs. 255 i 349; Baucells, et al. 2006, docs. 254 i 474; Baraut 1980 , doc. 314.

${ }^{45}$ Rius 1945-1947, docs. 65-66.
} 
no explicita el seu càrrec fins l'any 966, com a marmessor del comte Miró ${ }^{46}$. El nou vescomte fou investit en un període de represa d'hostilitats que s'obre amb l'atac contra els districtes de Tortosa l'any 964, previsiblement amb el setge infructuós de la ciutat de Tarragona. Poc després Guitard resoldria temporalment el conflicte en viatjar a Còrdova carregat de presents, amb el compromís que els comtes destruïssin les fortaleses que perjudicaven les fronteres. Tot seguint els passos de son pare, l'any 971 és Ènnec Bonfill qui protagonitza una nova ambaixada cordovesa. Aquí Ėnnec, fill de Sendred, és home de confiança de Borrell i el seu avançat sobre les seves fortaleses i principals ciutats, figura al capdavant d'una nodrida representació de cavallers i lliura una missiva de pau del seu senyor acompanyada de trenta captius musulmans que són alliberats. Amb Ènnec hi anava una legació paral·lela del vescomte Guitard, qui encara hi tornaria de nou l'any 974 amb una altra ambaixada imperial i amb l'emissari del bisbe de Girona. Cal recordar que és Guitard, senyor de la ciutat de Barcelona com el defineix Ibn Ḥayyān, qui aconsegueix adscriure el vescomtat barceloní permanentment al propi llinatge, $\mathrm{i}$ això gràcies al matrimoni dels seus fills amb dues filles del comte Borrell ${ }^{47}$.

Com a lloctinent comtal Ènnec no es prodiga gaire fora del comtat de Barcelona i quan ho fa és al de Manresa, on puntualment representa el comte Borrell sense gaire èxit. Aquí fracassa en reclamar l'alou de Vallformosa als seus habitants en 977, així com l'any 996 perd el plet que interposen els hereus del veguer Sal·la sobre les dècimes dels alous que reclamava a L'Espelt, Valldòria i Serraïma. També és testimoni privilegiat l'any 986 en la concessió de llibertats als habitants del castell de Cardona, comprà terres comtals al puig d'Abella (Òdena) i un document fals afirma que el bisbe de Vic li encomanà la meitat del castell de Miralles, que el comte cedí a la catedral en $987^{48}$.

$\mathrm{Al}$ comtat de Barcelona no resulta fàcil destriar les actuacions públiques que Ènnec protagonitza d'aquelles que corresponen a la seva activitat privada. Sembla actuar com agent comtal l'any 980 en obtenir de l'abat de Ripoll la concessió del lloc d'Olesa de Montserrat a canvi d'un cens anual, tot posseint els castells de Sacama i d'Esparreguera que comparteix amb els Gurb, així com confisca certes terres a Reixac. També revesteix un cert caràcter públic la compra al comte Borrell en 988 de nombroses terres vacants per causa de l'atac d'al-Manșūr a la ciutat de Barcelona, a canvi de 30 pesas que hauria d'invertir per reforçar les defenses urbanes, al Castell Nou que hom bastí sobre la muralla de ponent. Igualment, Ènnec comprà terres comtals al

\footnotetext{
${ }^{46}$ Fàbrega 1995, doc. 89; Sobrequés, et al. 2003, doc. 377.

${ }^{47}$ Bramon 2000, pp. 313-324; Ruiz-Domènec 2006, p. 36.

${ }^{48}$ Udina 1951, doc. 181; Ordeig 1999, docs. 1512-1513, 1736 i 1823; Galera 1998, doc. 7.
} 
castell de Cervelló i en 992 adquiria la pròpia fortificació, a més d'un alou a Plegamans, el fisc vallesà de valle Olofredi (Vallgorguina) o unes terres fiscals als termes de Caldes de Montbui i Sentmenat del Vallès. Present sovint a la cort, Ènnec ocupa posicions preferents en altres judicis públics i subscriu alienacions comtals de béns radicats a terres de Barcelona ${ }^{49}$.

En l'àmbit privat, Ènnec també protagonitza nombroses transaccions a la ciutat de Barcelona i al seu entorn immediat, així com al Vallès i al Penedès, especialment al terme d'Olèrdola, referides a béns que sovint se situen a prop d'altres propietats dels seus parents, amics i clients, als quals recolza puntualment en funcions de marmessor o testimoni. La seva última notícia correspon a l'any 1003 , quan protagonitza una darrera venda ${ }^{50}$. D'acord amb les sèries documentals, considerem molt probable que Ènnec hagi obtingut la fortificació de Gelida per concessió comtal, una posició preferent que completà amb l'adquisició dels castells de Masquefa i de Cervelló. També sospitem, però, que la donació del castell de Gelida al monestir de Sant Cugat i la seva recuperació l'any 998 a canvi d'altres béns poden encobrir l'apropiació definitiva del mateix. Hereva principal d'Ênnec i Eiga al comtat de Barcelona, el matrimoni de la seva filla El-liarda amb Hug, de la família dels veguers de Gurb, fusionava aquestes nissagues i originava el llinatge baronial dels Cervelló.

Finalment, Sendred Màger resulta ser el més opac dels tres fills de Sendred, l'únic germà que no ve referit amb el càrrec de veguer i que podria haver estat prevere. Casat amb Sança, aquesta és gairebé una desconeguda de nom insòlit aleshores i que suggereix arrels foranes. Podria ser filla, però, d'una altra Sança que en 963 donava al monestir de Montserrat l'església de Santa Coloma de Gorgonçana (Esparreguera), acompanyada del testimoni de Calabuig (Chalaber), que considerem el seu espòs. Així ho deduïm de les diverses donacions que l'any 985 realitza un tal Guillem a la Seu de Vic, també en remei de la difunta Sança, entre les quals el castell d'Esparreguera, amb l'excepció de les propietats paternes situades a Barcelona i al Penedès ${ }^{51}$. Ateses les seves propietats, considerem que aquest Guillem fou fill del levita Longobard, resident a Barcelona i fill del veguer Sal·la, el fundador de Sant

49 Ordeig 1999, docs. 1296 i 1644; Ordeig 2000-2008, doc. 669; Baucells, et al. 2006, doc. 129; Fàbrega 1995, docs. 144, 168, 178, 201 i 240; Rius 1945-47, docs. 190, 239, 243, 317, 337 i 343; Udina 1951, docs. 225 i 232; Feliu, Salrach (dirs.) 1999, docs. 44 i 46; Biblioteca de Catalunya, Manuscrits, P. Pasqual, Sacrae Antiquitatis 3, f. 7r, any 984.

${ }^{50}$ Udina 1947, doc. 1; Rius 1945-1947, docs. 117, 136-137, 144, 150, 277, 298, 327-328, 331, 351, 368, 382 i 398; Fàbrega 1995, docs. 146, 162, 182, 238 i 293; Udina 1951, docs. 202 i 229; Feliu, Salrach (dirs.) 1999, docs. 22-23, 26 i 69; Puig 1995, doc. 138; Biblioteca de Catalunya, Pergamins, 95, 2148, any 996.

${ }^{51}$ Altés 1994, doc. 45; Junyent 1980-1996, doc. 517. 
Benet de Bages ${ }^{52}$. I cal recordar que entre els fills de Sal-la també hi figura el prevere Guadamir, molt probablement germanastre de Calabuig i Llunès. Són correspondències que al capdavall justificarien l'apropiació de Castellvell de la Marca per part del llinatge dels Castellvell, quan Sendred Màger i Sança moriren sense descendència.

Les poques notícies segures que coneixem d'aquests esposos els situen a l'entorn d'Olèrdola, vers Avinyó del Penedès i Les Gunyoles, principalment en la resolució vers 992 del llarg conflicte que enfrontava Sendred Màger i el bisbe Vives, que considerem el seu cosí. En coincidència amb la consagració de l'església de Sant Pere del castell d'Avinyó, aleshores reconeixien haver posseït injustament fins aquí les dècimes i primícies d'aquesta fortificació, que pertanyien a Sant Miquel d'Olèrdola i que ara donaven a la catedral de Barcelona, tot reservant-se l'usdefruit vitalici. Iniciada la usurpació en temps de son pare, Sendred Màger no corregí l'error fins que Vives aconseguí tancar aquesta vella reclamació, que ara reduïa el castell d'Avinyó a simple quadra dependent d'Olèrdola (sua quadra). La iniciativa episcopal respon, però, a uns objectius més ambiciosos, atès que, un cop sotmesa la fortificació d'Avinyó, en aquest sector del Penedès va venir a suplantar-la el castell de La Granada, on la Seu de Barcelona i els seus col-laboradors invertiran abundants recursos durant dècades. Finalment Sendred optà per cedir l'alou d'Avinyó al monestir de Sant Cugat i podria ser mort en 997, mentre que Sança el sobreviuria fins l'any 1002, si més no ${ }^{53}$.

D'altra banda, observem que als textos referits hi consta la seva signatura autògrafa, amb el nom de Sendred i emmarcada per signes de subscripció. És per això que, a tall d'hipòtesi, pensem identificar el mateix personatge amb un prevere homònim que posseeix una signatura similar i que subscriu o redacta certs documents relatius a Cervelló durant el període 973-982, tot precedint la compra del castell per part d'Ènnec Bonfill ${ }^{54}$. I remarquem també que el prevere Sendred fou un dels marmessors del veguer Galí de Les Gunyoles, el seu veí.

Amb la desaparició dels tres fills del veguer Sendred, vers el canvi de mil·lenni arribà l'hora d'establir les senyories dels successors respectius. Sense que Sendred Màger ni Ènnec Bonfill tinguessin descendència masculina i en un to més discret que abans, el tronc familiar principal persistí en la nissaga d'Onofre Amat, amb dos fills coneguts, Guillem i Otger, que ara adopten respectivament els apel-latius de Castellvell i de Castellet i que seran els últims que s'intitulin veguers en aquesta família. Ara enemistat amb els

\footnotetext{
${ }^{52}$ Gibert [en prensa].

${ }^{53}$ Fàbrega 1995, docs. 125, 224-225 i 312; Rius 1945-1947, docs. 382 i 486.

${ }^{54}$ Rius 1945-1947, docs. 97, 136-137 i 144.
} 
seus parents, és amb el bisbe Vives i els seus fidels que l'Església comença a interferir en l'acció comtal i vicarial, un problema que s'agreuja durant la primera meitat del segle XI i més enllà, en coincidència amb l'adveniment dels usos feudals.

\section{CONCLUSIONS}

Tot resseguint les primeres generacions dels Castellvell hem comprovat que es tracta d'un llinatge aristocràtic que es remuntaria al segle IX i que disposa d'un poder manifest a les primeres actuacions conegudes. La seva és una sòlida família troncal amb una nítida successió patrilineal que prima la figura del primogènit, l'hereu que rep la porció principal del patrimoni, un tipus de transmissió que no és l'única forma d'heretament possible. Els seus actius, però, els conformen béns de diversa procedència i que són bons indicadors de la seva trajectòria.

La base patrimonial la integren les nombroses propietats alodials que posseeixen a la ciutat de Barcelona i al seu entorn immediat, o també al Vallès Oriental i al Maresme, a més d'alguns drets residuals a la diòcesi de Girona. En data incerta aquest nucli fundiari incorporà el Castellvell de Rosanes, que els reportaria el domini de bona part del Baix Llobregat o que els facilitaria noves adquisicions durant la conquesta i ocupació de la Marca del comtat, on el veguer Sendred participa activament. És sobre aquesta primera fortificació que pivota l'èxit definitiu del llinatge, un castell preexistent quan ells arribaren.

Gràcies als avenços arqueològics avui hom comença a reconèixer les fortificacions que cal atribuir a l'etapa andalusina, quan s'introdueixen i es desenvolupen les torres de guaita de planta circular, també a les comarques situades a ponent del riu Llobregat. Entre elles destaquen la torre del Castellvell de Rosanes i el cas penedesenc de Les Gunyoles, que segueixen els primers models edilicis del segle VIII. Com elles, moltes altres torres de característiques diversificades també haurien precedit aquí l'expansió comtal, tot integrant un dispositiu de vigilància territorial que enllaçava la vall del Llobregat amb el Camp de Tarragona. Són fortificacions específiques que cal estudiar amb molta cura i sistemàticament, així com és necessari d'aprofundir també en l'estudi de les torres residencials polimorfes i els primers recintes fortificats, que aquí habitualment constitueixen el nucli dels nous castells bastits amb l'ocupació comtal del segle X.

Els Castellvell mai necessitaren provar l'origen dels seus drets sobre la vella fortificació del Llobregat, un castell d'important valor estratègic per a la defensa de la ciutat de Barcelona i que s'ignora quan el prengueren 
les forces comtals. Opinem, però, que el context més idoni ens situa durant la segona meitat del segle IX, potser en temps dels marquesos Humfrid i Bernat de Gòtia o del comte Sunyer d'Empúries, quan un primer membre del llinatge l'ocuparia, dues generacions abans de la primera notícia conservada. De fet, així ho suggereixen els predis familiars del Montseny i del Tordera, que se situen entre els dominis d'aquells comtes. Així mateix, també inferim que els Castellvell haurien estat lloctinents comtals des d'un principi, atesa la posició que ocupen i els enllaços que estableixen amb certs llinatges vescomtals.

Malgrat tot, durant el segle X els Castellvell no transcendeixen la condició vicarial, encara que disposin d'àmplies prerrogatives de representació comtal, tant com ambaixadors i lloctinents a la Marca com en tasques judicials o dispositives. Són aquestes les funcions extraordinàries que desenvolupen Sendred i Ènnec Bonfill, ambdós reconeguts com veguers i senyors, mots que encara fan curt a la llum de les tasques que assoleixen. Són prerrogatives més pròpies d'un majordom de palau o d'un senescal avant la lettre, com succeeix amb la construcció del Castell Nou de Barcelona, fortificació que serà un dels bastions dels futurs senescals. També observem, però, que les competències que Ènnec desenvolupa pateixen serioses limitacions fins i tot al comtat de Barcelona, on altres veguers són els seus iguals, o fora d'aquí, on només intervé al comtat de Manresa amb resultats decebedors. De fet, en recórrer les petjades dels Castellvell durant el segle X hem retrobat altres llinatges vicarials presents al comtat aleshores, amb una destacada representació de veguers d'ascendència osonenca. També són llinatges coneguts d'antic i que caldria revisar, atès que els primers veguers habitualment provenen de les velles aristocràcies regionals.

No serà fins la fi de segle X que el comte Ramon Borrell promogui la creació d'oficis palatins diversificats, amb noves tasques com les de custodi i prebost que assignarà a certs primats. Aquests primers càrrecs explícits, però, no arrelen més enllà de la mort del comte, desaparegut quan s'enceta un llarg període de crisi entre la cort i l'Església. És aleshores que les famílies vicarials deixen de ser-ho, quan la vella aristocràcia i una nova noblesa adopten els locatius dels seus dominis principals. Al capdavall un bon nombre de concessions precàries també s'han transformat en drets hereditaris o alodials, tot seguint procediments diversos. En això els Castellvell disposen d'una àmplia gamma de recursos i més enllà del segle $\mathrm{X}$ el seu llinatge encara constitueix un cas axiomàtic, atès que il·lustra el paper que adopta l'aristocràcia dominical durant el procés d'implantació de la feudalitat. 


\section{BIBLIOGRAFIA CITADA}

Abadal, Ramon d' (1926-1950), Catalunya Carolíngia. Els diplomes carolingis a Catalunya II, Barcelona, IEC.

Abadal, Ramon d' (1958), Els primers comtes catalans, Barcelona, VicensVives.

Altés, Francesc X. (1994), El diplamatari del monestir de Santa Cecília de Montserrat, "Studia Monastica" 36, pp. 223-302.

Baiges, Ignasi; Feliu, Gaspar; Salrach, Josep Ma (dirs. 2010), Els pergamins de l'Arxiu Comtal de Barcelona, de Ramon Berenguer II a Ramon Berenguer IV, Barcelona, Fundació Noguera.

Ballestín, Xavier (1999), L'anomenada frontera superior d'al-Andalus: aț-tag்r al-a'là i la resistència a la instauració de la dawla dels Banū Marwān, en Musulmans i Catalunya, Barcelona, Empúries, pp. 61-76.

Baraut, Cebrià (1979), Els documents dels segles IX i X conservats a l'Arxiu Capitular de la Seu d'Urgell (anys 805-980), "Urgellia” 2, pp. 7-145.

Baraut, Cebrià (1980), Els documents dels anys 981-1010, de l'Arxiu Capitular de la Seu d'Urgell, "Urgellia" 3, pp. 7-166.

Baucells, Josep; Fàbrega, Àngel; Riu, Manel; Hernando, Josep; Batlle, Carme (2006), Diplomatari de l'Arxiu Capitular de la Catedral de Barcelona: Segle XI, Barcelona, Fundació Noguera.

Benet, Albert (1982), El Bages nucli de vida monàstica de tradició visigòtica?, "Dovella" 4, pp. 12-19.

Benet, Albert (1983), L'origen de les famílies Cervelló, Castellvell i Castellet, "Acta Historica et Archaeologica Mediaevalia" 4, pp. 67-86.

Bolòs, Jordi (2000), Els castells medievals a Catalunya, en L'arquitectura militar medieval. Jornades d'Història i Arqueologia Medieval del Maresme, Mataró, Grup d'Història del Casal, pp. 11-23.

Bolòs, Jordi; Pagès, Montserrat (1986), El castell i la baronia de Castellví de Rosanes (Baix Llobregat). Fortaleses, torres, guaites $i$ castells de la Catalunya medieval, en Acta Mediaevalia. Annex 3, Barcelona, Universitat de Barcelona, pp. 113-151.

Bonnassie, Pierre (1975-1976), La Catalogne du milieu du Xe a la fin du XI siècle. Croissance et mutations d'une société, Toulouse, Université Toulouse - Le Mirail.

Bramon, Dolors (2000), De quan érem o no musulmans. Textos del 713 a 1010, Vic - Barcelona, Eumo.

Coll, Jaume (1988-89), Els vescomtes de Girona, “Annals de l'Institut d'Estudis Gironins" 30, pp. 39-98.

Durán, Félix (1927), El señorío de Castellvell, Tarragona, Real Sociedad Arqueológica. 
Fàbrega, Àngel (1995), Diplomatari de la Catedral de Barcelona. Documents dels anys 844-1000, Barcelona, Catedral de Barcelona.

Feliu, Gaspar (1984), El bisbe Vives de Barcelona i el patrimoni de la catedral (974-995), en Miscel-lània d'homenatge a Miquel Coll i Alentorn en el seu vuitantè aniversari, Barcelona, Barcino, pp. 167-191.

Feliu, Gaspar; Salrach, Josep M ${ }^{\mathrm{a}}$ (dirs.) (1999), Els pergamins de l'Arxiu Comtal de Barcelona de Ramon Borrell a Ramon Berenguer I, Barcelona, Fundació Noguera.

Fité, Francesc (1986), Les torres de guaita de la Catalunya de Ponent. Alguns exemples de l'àrea del Montsec, en Setmana d'Arqueologia Medieval, Lleida, IEI, pp. 25-98.

Galera, Andreu (1998), Diplomatari de la vila de Cardona (anys 966-1276), Barcelona, Fundació Noguera.

Garí, Blanca (1985), El linaje de los Castellvell en los siglos XI-XII, Bellaterra, Universitat Autònoma de Barcelona.

Garí, Blanca (1990), Problemas paleográficos y diplomáticos en la documentación del siglo X referente a un linaje, "Medievalia" 9, pp. 133-152.

Gibert, Jordi (2006), La torre sobirana de Castellví de Rosanes, un edifici vinculat a la conquesta islàmica, "Materials del Baix Llobregat" 12, pp. 53-57.

Gibert, Jordi (2011), L'Alta Edat Mitjana a la Catalunya Central. Estudi històric $i$ arqueològic de la conca mitjana del riu Llobregat, Bellaterra, Universitat Autònoma de Barcelona (tesi doctoral).

Gibert, Jordi (en premsa), Del Conflent a la Conca d'Òdena. La família del veguer Sal-la en el marc de l'expansió del comtat d'Osona-Manresa al segle $X$, "Miscellania Aqualatensia".

Gonzalo, Xavier (2011), Dinàmiques d'organització social $i$ territorial in territorio Terrachone. Estudi històrico-arqueològic del territori de la ciutat de Tarracona / Tarrakūna / Terrachona i els seus marges ( $s$. VII-X dne), Toulouse, Mémoire M2R Études Médiévales, Université Toulouse II - Le Mirail.

Gonzalo, Xavier; Martí, Ramon (2015), El poblament altmedieval del territori de Tarragona: campanyes de prospecció arqueològica a l'Alt Camp i la Conca de Barberà (2012-2013). Primers resultats, en $V$ Congrés d'Arqueologia Medieval i Moderna a Catalunya, Barcelona ACRAM, pp. 721-728.

Hautefeuille, Florent (2009), Les vigueries carolingiennes en Quercy et en Toulosain, "Annales du Midi. Revue de la France méridionale" 121, pp. 199-213.

Jarret, Jonathan (2010), Archbishop Ató of Osona. False Metropolitans in the Marca Hispanica, "Archiv für Diplomatik Schriftgeschichte, Siegelund Wappenkunde" 56, pp. 1-42. 
Junyent, Eduard (1980-1996), Diplomatari de la Catedral de Vic. Segles IX-X, Vic, Patronat d'Estudis Osonencs.

Lauranson-Rosaz, Christian (2009), La vicaria en Auvergne et dans ses marges (IX-X siècle). Le cadre politique, spatial et social d'une circonscription civile carolingienne, "Annales du Midi. Revue de la France méridionale" 121, pp. 215-235.

Llop, Irene (2009), Col·lecció diplomàtica de Sant Pere de Casserres, Barcelona, Fundació Noguera.

Martí, Ramon (1992), La primera expansió comtal a ponent del Llobregat, en Catalunya Romànica, vol. XIX, Barcelona, Enciclopèdia Catalana, pp. 28-35.

Martí, Ramon (1994), Delà, Cesari i Ató, primers arquebisbes dels comtesprínceps de Barcelona (951/953-981), "Analecta Sacra Tarraconensia" 67/1, pp. 369-386.

Martí, Ramon (1997), Col-lecció diplomàtica de la Seu de Girona (817-1100), Barcelona, Fundació Noguera.

Martí, Ramon (ed.) (2008), Fars de l'islam. Antigues alimares d'al-Andalus, Barcelona, Edar.

Martí, Ramon; Colomer, Jordi (2011), Monasteriola: petits monestirs d'antiga fundació, en Els monestirs medievals catalans. IV Jornades d'Història i Arqueologia medieval del Maresme, Mataró, Grup d'Història del Casal, pp. 84-96.

Mauri, Alfred (2006), La configuració del paisatge medieval: el comtat de Barcelona fins el segle XI, Barcelona, Universitat de Barcelona (tesi doctoral).

Mauri, Alfred (2014), El Castellvell de Rosanes, Martorell, Centre d'Estudis Martorellencs.

Menchón, Joan (2011), La torre de Vallferosa (Torà, La Segarra). Aproximació a la seva arquitectura i datació radiocarbònica, en Actes del IV Congrés d'Arqueologia Medieval i Moderna a Catalunya, Tarragona, ACRAM, pp. 769-782.

Miquel, Júlia (2001), Els Cervelló, barons de Querol-Montagut a l'Edat Mitjana, "Miscel-lània Penedesenca" 26, pp. 165-201.

Molist, Núria; Bosch, Josep Ma (2012), El cementiri medieval de Sant Miquel d'Olèrdola (Olèrdola, Alt Penedès), en Arqueologia funerària al nord-est peninsular (segles VI-XII), Barcelona, Museu d'Arqueologia de Catalunya-Olèrdola, pp. 469-494.

Muntaner, Ignasi Maria (2012), La Vallmoll i la Via Morisca, "Del Penedès" 27-28, pp. 61-71.

Ordeig, Ramon (1993-2001), Les dotalies de les esglésies de Catalunya (segles IX-XII), Vic, Estudis Històrics. 
Ordeig, Ramon (1999), Catalunya Carolíngia. Els comtats d'Osona i Manre$s a$, vol. IV, Barcelona, IEC.

Ordeig, Ramon (2000-2008), Diplomatari de la Catedral de Vic. Segle XI, Vic, Patronat d'Estudis Osonencs.

Pedemonte, Bonaventura (1929), Notes per a la Història de la Baronia de Castellvell de Rosanes, Barcelona, Etzeviriana.

Pladevall, Antoni (1990), Sant Martí d'Empúries, en Catalunya Romànica. L'Empordà, vol. IX, Barcelona, Enciclopèdia Catalana, pp. 466-468.

Pladevall, Antoni (1992), Sant Esteve de Castellet (o de Can Llopard o de les Masuques), en Catalunya Romànica. El Penedès. L'Anoia, vol. XIX, Barcelona, Enciclopèdia Catalana, pp. 105-106.

Ponsich, Pere (2006), Catalunya Carolíngia. Els comtats de Rosselló, Conflent, Vallespir i Fenollet, vol. VI, Barcelona, IEC.

Puig, Pere (1995), El monestir de Sant Llorenç del Munt sobre Terrassa. Diplomatari dels segles X $i$ XI, Barcelona, Fundació Noguera.

Riu, Manel (1985-1986), L'aportació de l'arqueologia a l'estudi de la formació i expansió del feudalisme català, "Estudi General" 5-6, pp. 27-45.

Rius, José (1945-1947), Cartulario de Sant Cugat del Vallés, Barcelona, CSIC.

Roura, Gabriel (1985-1986), Un diploma desconegut del rei Odó a favor del seu fidel Wicfrid (888-898), "Estudi General” 5-6, pp. 65-75.

Ruiz-Domènec, José Enrique (1982), La primera estructura feudal (consideraciones sobre la producción, el poder y el parentesco en Cataluña durante el siglo XI, c. 980-c. 1060), "Quaderni Catanesi di Studi Classici e Medievali" 4/8, pp. 301-368.

Ruiz-Domènec, José Enrique (2006), Quan els vescomtes de Barcelona eren, Barcelona, Fundació Noguera.

Schneider, Laurent (2007), In regno Septimanie, in comitatu et territorio Biterrensi. Le Biterrois et l'aristocratie biterroise de la fin $d u I X^{e} s . \grave{a}$ la fin $d u X^{e} s$., "Annales du Midi. Revue de la France méridionale" 119, pp. 409-456.

Sobrequés, Santiago; Riera, Sebastià; Rovira, Manuel; Ordeig, Ramon (2003), Catalunya Carolíngia. Els comtats de Girona, Besalú, Empúries $i$ Peralada, vol. V, Barcelona, IEC.

Udina, Federico (1947), El "Llibre Blanch" de Sentas Creus, Barcelona, CSIC.

Udina, Federico (1951), El Archivo Condal de Barcelona en los siglos IX-X, Barcelona, CSIC.

Fecha de recepción del articulo: enero 2015

Fecha de aceptación y versión final: noviembre 2015 